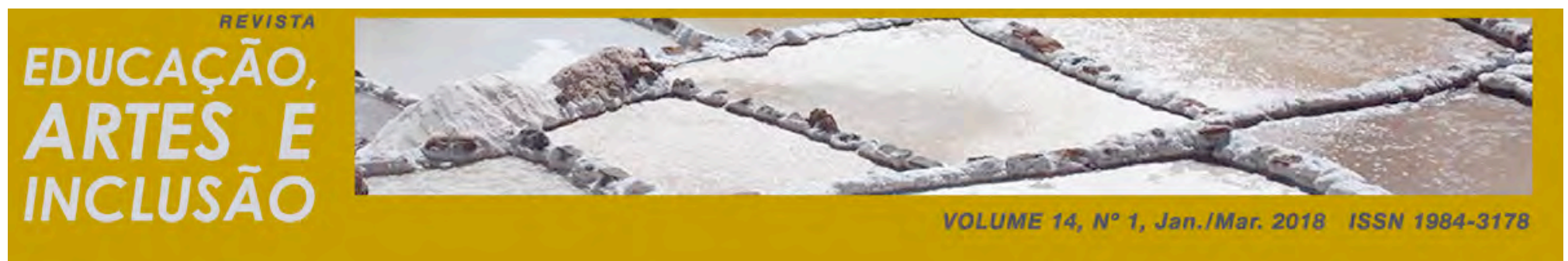

\title{
ENTRE CORES E PESSOAS COM VISÃO SUBNORMAL
}

\section{BETWEEN COLORS AND PEOPLE WITH SUBNORMAL VISION}

DOI: http://dx.doi.org/10.5965/1984317814012018062

\author{
Robson Xavier da Costa e Viviane dos Santos Coutinho - Universidade Federal da Paraíba
}

\begin{abstract}
RESUMO
Nesta investigação analisamos o impacto das cores no cotidiano e na fruição de imagens artísticas em pessoas com visão subnormal. Desenvolvemos pesquisa qualitativa com o método do estudo de caso (YIN, 2005) no ano de 2016, no Instituto dos Cegos da Paraíba Adalgisa Cunha (ICPAC), na cidade de João Pessoa. A pesquisa foi feita com pessoas com visão subnormal a partir da observação in loco das dificuldades de identificação das cores que as crianças e jovens do ICPAC apresentam. Estudamos um grupo três estudantes com visão subnormal, com idade de 6,8 e 16 anos. Utilizamos estímulos visuais variados, objetivando medir a distinção de cores/texturas e cores/aromas. Os resultados apontam que os participantes apresentaram dificuldades para enxergar as cores na maior ou menor incidência de iluminação direta; a luz intensa torna seus olhos sensíveis, causando irritabilidade e vermelhidão; um ambiente totalmente escuro faz com que percam completamente a noção das cores; o contato com maquetes táteis com reproduções de obras de arte permitiu a identificação de formas, distinção figura/fundo e algumas cores, a percepção das obras foi significativa.
\end{abstract}

Palavras chave: Artes Visuais; Estudo de Caso; Deficiência Visual.

\begin{abstract}
In this research we analyze the impact of colors on daily life and the enjoyment of artistic images of people with low vision. We developed a qualitative research using the study case method (YIN, 2005) in the year 2016, at the Instituto dos Cegos de Paraíba Adalgisa Cunha (ICPAC), in the city of João Pessoa. The research was done with people with low vision from the observation in loco of the difficulties of identifying the colors that the children and youth of the ICPAC present. We studied a group of three students with low vision, among the ages of 6,8 and 16 years. We use varied visual stimuli, aiming to measure the distinction of colors/textures and colors/aromas. The results show that the participants presented difficulties to see the colors in the greater or lesser incidence of direct illumination; the intense light makes your eyes sensitive, causing irritability and redness; a totally dark environment causes them to lose completely the notion of colors; the contact with tactile models with reproductions of works of art allowed the identification of forms, distinction figure/background and some colors, the perception of the works was significant.
\end{abstract}

Keywords: Visual arts. Case Study. Visual Impairment. 


\section{PRA INÍCIO DE CONVERSA}

Esta pesquisa investigou o estudo da relação das cores no cotidiano de pessoas com visão subnormal. O estudo de caso (YIN, 2005) foi realizado com três estudantes ${ }^{1}$ que frequentaram o Instituto dos Cegos da Paraíba Adalgisa Cunha (ICPAC), em João Pessoa, Paraíba, Brasil, no ano de 2016. Foi um estudo de casos múltiplos, descritivo e qualitativo.

O ICPAC é uma instituição sem fins lucrativos; a primeira escola para deficientes visuais fundada no Nordeste, em 1948. Tem caráter assistencial e atende estudantes de baixa renda de todo o Estado da Paraíba e estados vizinhos. Está localizada no Bairro dos Estados, na cidade de João Pessoa. A pesquisa é uma continuidade do Projeto de Pesquisa Artes Visuais \& Inclusão; sendo uma pesquisa ligada ao Grupo de Pesquisa em Arte, Museus e Inclusão (GPAMI) e ao Laboratório de Artes Visuais Aplicadas e Integrativas (LAVAIS), da Universidade Federal da Paraíba (UFPB).

O foco no uso das cores por pessoas com visão subnormal foi definido a partir da observação da dificuldade que essas crianças e jovens apresentavam durante as atividades de artes visuais no ICPAC, considerando que a simbologia das cores tem como principal limitação à percepção visual.

O estudo de campo foi aplicado com pessoas com visão subnormal, com idade de 6,8 e16 anos; com atendimentos individuais, com encontros semanais de quarenta e cinco minutos. Para estes estudantes apresentamos cores em vários meios e tamanhos: manchas coloridas em fundos brancos, riscos coloridos, folhas coloridas, etc., algumas criações artísticas e as produções visuais dos próprios estudantes.

Durante o processo estimulamos diferenciações entre cores/texturas e cores/aromas, utilizando as cores e suas possíveis atribuições. Como o exemplo do algodão e a textura macia, que comumente é representada pela cor branca, que representam Paz no Ocidente. Foram feitas associações que lhes são familiares e que fossem capazes de provocar sensações ou lembranças.

\footnotetext{
${ }^{1}$ Servidores e técnicos do Instituto dos Cegos da Paraíba Adalgisa Cunha utilizam o termo "usuário" para identificar os estudantes.
} 
Relacionamos as cores à visão subnormal devido ao seu simbolismo, já que representam sentimentos, emoções, objetos, momentos vividos, etc. As cores podem ganhar significados reais por meio de associações táteis, olfativas e até gustativas, deixando de ser meramente visuais e passando a ter significado por meio de texturas, aromas e gostos, a partir das experiências vividas, pois "as coisas visuais não são simplesmente algo que está ali por acaso. São acontecimentos visuais, ocorrências totais, ações que incorporam a reação ao todo" (DONDIS, 2007, p.31).

As cores são capazes de produzir sensações, reflexões e impressões diferentes para cada sujeito. A influência das cores no modo como nos vestimos, nos ambientes que convivemos, etc., são essenciais para a adaptação das pessoas no cotidiano; as cores de nossas preferências podem identificar nossa personalidade.

As cores interferem em nossas escolhas e, consequentemente, em nossas reações, orientando-nos. E, sendo a cor, importante causador de emoções, se tivermos conhecimentos sobre seus efeitos, podemos tê-las como aliadas, utilizando-as como um recurso construtivo. A escolha das cores pode ser baseada na personalidade, em circunstâncias, em seus desejos, em sua mentalidade, etc., influenciando nossos componentes físico, mental e emocional.

As pessoas com visão subnormal se deparam no cotidiano com maiores dificuldades ao caminhar nas ruas do que os normovisuais ${ }^{2}$. Os sinais de trânsito nem sempre são sonoros e a influência da luz faz com que as pessoas com visão subnormal não identifiquem quais as cores no semáforo. Nos ônibus urbanos nem sempre há sinal sonoro e nos pontos de ônibus para a pessoa com visão subnormal não é possível identificar o seu destino. Além disto, nem todas as pessoas com visão subnormal conhecem as cores; não sabem ou não identificam qual a cor da faixa de pedestre, a cor da roupa que estão usando, nem a cor de seus olhos, de seu cabelo, etc. As cores geralmente não lhes são apresentadas devido a sua deficiência.

Partindo da análise comparativa da influência das cores na vida dos sujeitos da pesquisa, analisamos como o contato diário com as cores pode interferir na vida das pessoas com visão subnormal e como estratégia utilizamos a pesquisa qualitativa (RICHARDSON,

\footnotetext{
2 Termo utilizado por VENTORINI, Silvia Helena. A experiência como fator determinante na representação espacial da pessoa com deficiência visual. São Paulo: UNESP, 2009.
} 
2012) e o estudo de caso (YIN, 2005), registramos e interpretamos os fatos. Todo o processo foi documentado e após a coleta de dados, foi feita uma análise das relações e dos efeitos das cores no grupo pesquisado.

O objetivo geral da pesquisa foi analisar o impacto das cores no cotidiano e na fruição de imagens artísticas em pessoas com visão subnormal. Os objetivos específicos foram: identificar as principais dificuldades e usos de cores no cotidiano de pessoas com visão subnormal no ICPAC; desenvolver atividades expressivas com uso das cores no ensino de artes visuais para pessoas com visão subnormal no ICPAC e avaliar a percepção das cores no contato com imagens artísticas por pessoas com visão subnormal no ICPAC.

Para a investigação foi utilizada a metodologia desenvolvida por Yin (2005), em seu livro Estudo de caso - Planejamentos e Métodos. O estudo de caso utiliza-se de comparações, tendo como principais perguntas o "como?" e o "por quê?", pois são mais explicativas e lidam com os vínculos necessários a serem traçados ao longo do percurso. Há variações nos estudos de caso, podendo ser únicos ou múltiplos, quantitativos ou qualitativos. É a análise de como ocorreu e por que ocorreu.

Yin (2005, p.15) afirmou que questões "como" e "por que" são feitas sobre um conjunto de eventos contemporâneos ou sobre algo que o pesquisador tem pouco ou nenhum controle. De acordo com o autor:

Fazer um estudo de caso de forma apropriada significa ter em vista cinco preocupações tradicionais sobre estudo de caso - conduzir a pesquisa de forma rigorosa, evitar confusões com casos de ensino, saber como chegar a conclusões generalizadas quando desejado, gerir cuidadosamente o nível de esforço e compreender a vantagem comparativa da pesquisa de estudo de caso. O desafio geral torna a pesquisa de estudo de caso "difícil", apesar de ela ser classicamente considerada uma forma de pesquisa "leve" $(2015, \mathrm{p} .2)$.

O estudo de caso procura definir o caso a ser estudado, determinar dados relevantes e fazer uma análise de como essas coletas de dados podem contribuir significativamente para a pesquisa, apresentando as vantagens e desvantagens. 


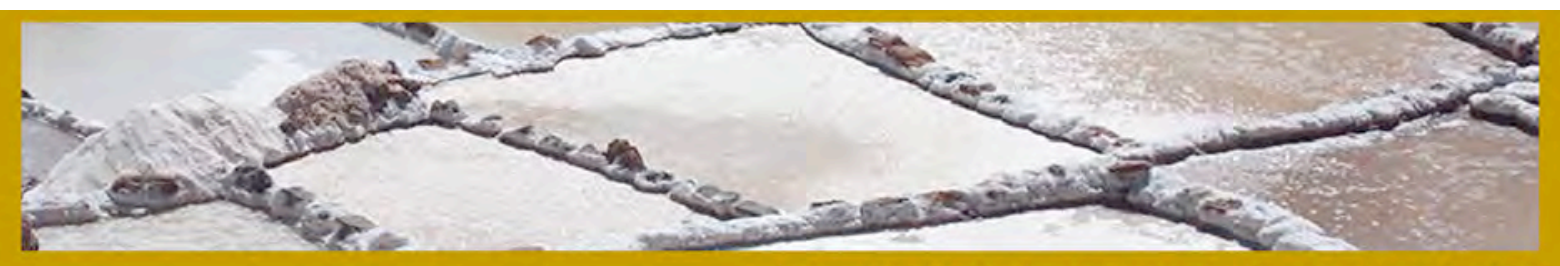

\begin{abstract}
Há, no mínimo, cinco aplicações diferentes [para o estudo de caso]. A mais importante é explicar os vínculos causais em intervenções da vida real que são complexas demais para as estratégias experimentais ou aquelas utilizadas em levantamentos. (...). Uma segunda aplicação é descrever uma intervenção e o contexto na vida real em que ela ocorre. Em terceiro lugar, os estudos de caso podem ilustrar certos tópicos dentro de uma avaliação, outra vez de um modo descritivo - mesmo de uma perspectiva jornalística. A quarta aplicação é que a estratégia de estudo de caso pode ser utilizada para explorar aquelas situações nas quais a intervenção que está sendo avaliada não apresenta um conjunto simples e claro de resultados. Em quinto lugar, o estudo de caso pode ser uma "meta-avaliação" (YIN, 2005, p. 34 - grifo nosso).
\end{abstract}

Ainda segundo o autor as questões de estudo vêm inicialmente das perguntas "como" e "por que" para se obter clareza; partindo para as proposições que refletem importantes questões teóricas que levam a dados onde o pesquisador fará a separação entre os dados mais relevantes e os irrelevantes. É essencial que o pesquisador saiba o porquê do estudo está sendo realizado e o que realmente busca em sua pesquisa.

Para Yin (2005) há cinco exercícios que auxiliam no projeto de pesquisa de estudo de caso, que são definir no estudo de caso: os limites, a unidade de análise, um projeto de pesquisa, o fundamento lógico para estudos de caso único e de casos múltiplos e os critérios para julgar a qualidade dos projetos de pesquisa.

Há seis fontes de evidencias em um estudo de caso, as quais requerem habilidades e metodologias para serem aplicadas: documentos, registros em arquivo, entrevistas, observação direta, observação participante e artefatos físicos. Além de outros princípios para a coleta de dados, como o uso de várias fontes de evidências, as evidências distintas reunidas a partir do relatório final do estudo e as ligações entre as questões que foram feitas, os dados e as conclusões a que chegou (quadro 01).

Quadro1: Fontes para Estudo de Caso segundo Yin (2005)

\begin{tabular}{|l|l|l|}
\hline $\begin{array}{c}\text { FONTES DE } \\
\text { EVIDENCIAS }\end{array}$ & \multicolumn{1}{|c|}{ PONTOS FORTES } & \multicolumn{1}{c|}{ PONTOS FRACOS } \\
\hline Documentação & $\begin{array}{l}\text { • Estável - pode ser revisada inúmeras } \\
\text { vezes }\end{array}$ & $\begin{array}{l}\text { @ Capacidade de recuperação - pode ser } \\
\text { baixa }\end{array}$ \\
\hline
\end{tabular}




\begin{tabular}{|c|c|c|}
\hline & $\begin{array}{l}\text { - Discreta - não foi criada como resultado } \\
\text { do estudo de caso } \\
\text { - Exata - contém nomes, referências e } \\
\text { detalhes exatos de um evento } \\
\text { - Ampla cobertura - longo espaço de } \\
\text { tempo, muitos eventos e muitos ambientes } \\
\text { distintos }\end{array}$ & $\begin{array}{l}\text { - Seletividade tendenciosa, se a coleta não } \\
\text { estiver completa } \\
\text { - Relato de visões tendenciosas - reflete as } \\
\text { ideias preconcebidas (desconhecidas) do } \\
\text { autor } \\
\text { - Acesso - pode ser deliberadamente } \\
\text { negado }\end{array}$ \\
\hline Registros em arquivos & $\begin{array}{l}\text { - Os mesmos mencionados para } \\
\text { documentação } \\
\text { - Precisos e quantitativos }\end{array}$ & $\begin{array}{l}\text { - Os mesmos mencionados para } \\
\text { documentação } \\
\text { - Acessibilidade aos locais graças a razões } \\
\text { particulares }\end{array}$ \\
\hline Entrevistas & $\begin{array}{l}\text { - Direcionadas - enfocam diretamente o } \\
\text { tópico do estudo de caso } \\
\text { - Perceptivas - fornecem inferências } \\
\text { causais percebidas }\end{array}$ & $\begin{array}{l}\text { - Visão tendenciosa devido a questões mal } \\
\text { elaboradas } \\
\text { - Respostas tendenciosas ocorrem } \\
\text { imprecisões devido à memória fraca do } \\
\text { entrevistado } \\
\text { - Reflexibilidade - o entrevistado dá ao } \\
\text { entrevistador o que ele quer ouvir }\end{array}$ \\
\hline Observações diretas & $\begin{array}{l}\text { - Realidade - trata de acontecimentos em } \\
\text { tempo real } \\
\text { - Contextuais - tratam do contexto do } \\
\text { evento }\end{array}$ & $\begin{array}{l}\text { - Consomem muito tempo } \\
\text { - Seletividade - salvo ampla cobertura } \\
\text { - Reflexibilidade - o acontecimento pode } \\
\text { ocorrer de forma diferenciada porque está } \\
\text { sendo observado } \\
\text { - Custo - horas necessárias pelos } \\
\text { observadores humanos }\end{array}$ \\
\hline $\begin{array}{l}\text { Observação } \\
\text { participante }\end{array}$ & $\begin{array}{l}\text { - Os mesmos mencionados para } \\
\text { observação direta } \\
\text { - Perceptiva em relação a comportamentos } \\
\text { e razões interpessoais }\end{array}$ & $\begin{array}{l}\text { - Os mesmos mencionados para observação } \\
\text { direta } \\
\text { - Visão tendenciosa devido à manipulação } \\
\text { dos eventos por parte do pesquisador }\end{array}$ \\
\hline Artefatos físicos & $\begin{array}{l}\text { - Capacidade de percepção em relação a } \\
\text { aspectos culturais } \\
\text { - Capacidade de percepção em relação a } \\
\text { operações técnicas }\end{array}$ & $\begin{array}{l}\text { - Seletividade } \\
\text { - Disponibilidade }\end{array}$ \\
\hline
\end{tabular}

Fonte: Yin, 2005

O estudo de caso se aplicou perfeitamente a esta investigação por estudarmos uma especificidade das Deficiências Visuais, a visão subnormal em crianças e jovens, o que ocorre 
em apenas $20 \%$ dos estudantes do o ICPAC $^{3}$, que tem cadastro de mais de 300 pessoas com algum tipo de deficiência visual ou alguma outra deficiência associada. Os atendimentos vão de recém-nascidos à idosos. Estes atendimentos ocorrem nos turnos da manhã e tarde. Dentre as atividades que os estudantes têm dentre da instituição, estão: estimulação visual, fisioterapia, fonoaudiologia, terapia ocupacional, comunicação alternativa por meio da música e alfabetização em Braille, atividades de vida diária (AVDs), aulas esportivas, etc. $\mathrm{Na}$ Instituição não havia atividades com artes visuais e o projeto Artes Visuais \& Inclusão da UFPB, foi aceito tanto pelos estudantes, como pelos profissionais.

A pesquisa tem sido acompanhada pela vice-diretora e também coordenadora de reabilitação do ICPAC, que apoia a investigação, dando abertura para pesquisas no campo das artes visuais no Instituto. Antes de iniciarmos a pesquisa conversamos com a vice-diretora e a psicóloga da instituição, definindo os estudantes que iriam participar da pesquisa. A psicóloga também informou como eram as outras atividades dos estudantes e como haviam tido contato com as cores até então.

\section{ASPECTOS HISTÓRICOS E SOCIAIS DA VISÃO SUBNORMAL}

O termo deficiência visual não significa, necessariamente, total incapacidade para ver, pois sob a deficiência visual poderemos encontrar pessoas com vários graus de visão residual (CONDE, 2012).

Segundo a Fundação Dorina ${ }^{4}$ (2012), a baixa visão caracteriza-se pelo comprometimento do funcionamento visual dos olhos, mesmo após tratamento ou correção. As pessoas com baixa visão podem ler e/ou identificar textos impressos, ampliados ou com uso de recursos óticos especiais, além de cores e formas ampliadas.

\footnotetext{
${ }^{3}$ Dados retirados do site do ICPAC. Disponível em: <http://icpac.com.br/conheca>. Acesso em 30 de Nov. 2016

${ }^{4}$ Fonte: http://www.fundacaodorina.org.br/deficiencia-visual/. Acesso em: 31 out. 2016
} 


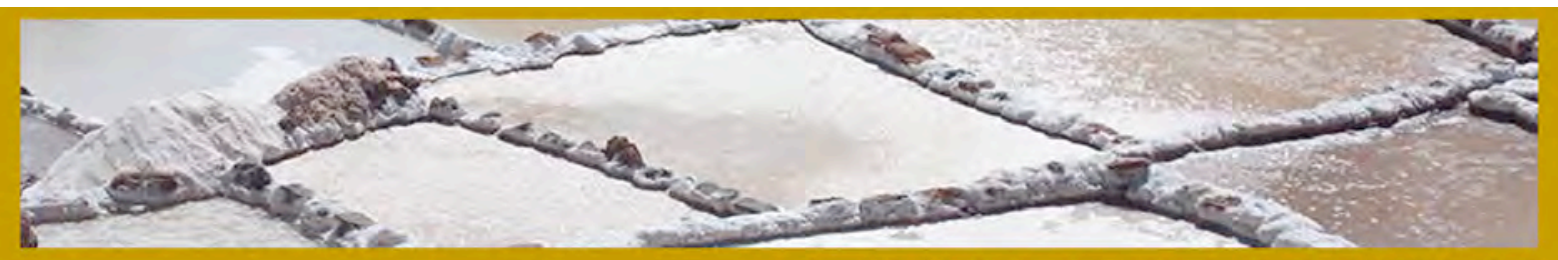

Os principais indícios relacionados à deficiência visual, segundo o site Visão Laser ${ }^{5}$ (2005), são: a constante irritação ocular, uma excessiva aproximação junto ao rosto para ler ou escrever, dificuldade para leitura à distância, esforço visual, inclinação da cabeça para tentar enxergar melhor, dificuldade de enxergar pequenos obstáculos no chão, nistagmo (olho constantemente trêmulo), estrabismo ou dificuldade de enxergar em ambientes claros.

O Conselho Brasileiro de Oftalmologia (2012, p. 10) nos fornece os seguintes dados sobre a acuidade visual pela distância:

\begin{tabular}{|c|c|c|}
\hline \multicolumn{3}{|c|}{ ACUIDADE VISUAL PELA DISTÂNCIA } \\
\hline Categoria & Pior que: & Igual ou melhor que: \\
\hline (Deficiência visual leve ou sem deficiência) & & $\begin{array}{c}6 / 18 \\
3 / 10(0,3) \\
20 / 70\end{array}$ \\
\hline Deficiência visual moderada & $\begin{array}{c}6 / 18 \\
3 / 10(0,3) \\
20 / 70\end{array}$ & $\begin{array}{c}6 / 60 \\
1 / 10(0,1) \\
20 / 200\end{array}$ \\
\hline $\begin{array}{c}2 \\
\text { Deficiência visual grave }\end{array}$ & $\begin{array}{c}6 / 60 \\
1 / 10(0,1) \\
20 / 200\end{array}$ & $\begin{array}{c}3 / 60 \\
1 / 20(0,05) \\
20 / 400\end{array}$ \\
\hline $\begin{array}{l}3 \\
\text { Cegueira }\end{array}$ & $\begin{array}{c}3 / 60 \\
1 / 20(0,05) \\
20 / 400\end{array}$ & $\begin{array}{c}1 / 60 * \\
1 / 50(0.02) \\
5 / 300(20 / 1200)\end{array}$ \\
\hline $\begin{array}{c}4 \\
\text { Cegueira }\end{array}$ & $\begin{array}{c}1 / 60 * \\
1 / 50(0.02) \\
5 / 300(20 / 1200)\end{array}$ & Percepção de luz \\
\hline $\begin{array}{c}5 \\
\text { Cegueira }\end{array}$ & & ção de luz \\
\hline 9 & Indeter & ão especificada \\
\hline
\end{tabular}

\footnotetext{
${ }^{5}$ Fonte: http://www.visaolaser.com.br/saude-ocular/doencas-oculares/baixa-visao/. Acesso em: 2 nov. 2016
} 
Onde "existem quatro níveis de função visual, de acordo com a Classificação Internacional de Doenças; que são: visão normal, deficiência visual moderada, deficiência visual grave e cegueira" (TALEB. et al., 2012, p. 10).

Segundo esse autor o Conselho Brasileiro de Oftalmologia afirma:

O CID atual usa as palavras "visão subnormal" para as categorias 1, 2 e 3 das deficiências visuais. Na prática dos cuidados visuais, "visão subnormal" tem um significado específico, definido pela OMS, que é o seguinte: "A pessoa com visão subnormal é aquela que possui uma deficiência da função visual mesmo após tratamento e/ou correção refrativa, apresentando acuidade visual de 20/60 ou menos e percepção de luz, ou um campo visual inferior a 10 graus de campo visual central, mas que usa sua visão, ou é potencialmente capaz de usá-la para o planejamento e/ou execução de uma tarefa". Por essa definição, pessoas que poderiam se beneficiar de tratamentos de baixa visão estão atualmente categorizadas como cegas. Isso levou a erros de cálculos de estimativas de pessoas que necessitam de tratamento para visão subnormal (TALEB. et. al. 2012, p. 12).

Baierle (2016) afirma que são mais de 45 milhões de brasileiros com alguma deficiência sensorial, motora ou intelectual e, destes, 35,8 milhões tem algum grau de deficiência visual. Ainda há muitos casos de pessoas com baixa visão que têm dificuldades em declarar-se deficiente visual temendo o preconceito social; relatando que isto ocorre devido à baixa visão nem sempre ser visível ou perceptível à primeira vista, pois "muitas [pessoas] não usam bengala e não são percebidas com facilidade" (BAIERLE, 2016).

Nos casos em que a deficiência visual é percebida tardiamente acaba prejudicando nos cuidados com a saúde ocular ou até mesmo agravando o problema. Não há padrões para definir a pessoa com visão subnormal, pois cada um terá um tamanho de fonte, contrastes de cores e luminosidade que podem identificar as distâncias, as formas, a luminosidade, etc. Cada caso apresente limitações e potencialidades diferentes.

As principais causas evitáveis da cegueira, segundo o Conselho Brasileiro de Oftalmologia são: cicatrizes corneanas, catarata; glaucoma, retinopatia da prematuridade; 
erros de refração e baixa visão (esta engloba a deficiência visual e cegueira por causas intratáveis). De acordo com o Conselho Brasileiro de Oftalmologia:

Estima-se que há 1,4 milhões de crianças cegas no mundo, das quais, segundo o Plano de Ação do Programa Visão 2020 para 2006/2011, um milhão vivem na Ásia e 300.00 na África. A prevalência varia de $0.3 / 1000$ crianças de $0-15$ anos em países desenvolvidos para 1.5/1.000 crianças em países muito pobres. Embora o número de crianças cegas seja relativamente baixo, elas têm uma longa expectativa de vida. Se multiplicarmos o número de crianças pela sua expectativa de vida, chegaremos a uma estimativa de 75 milhões de anos-cego, um número menor apenas do que o número de anos-cego da catarata em idosos (TALEB. et. al. 2012, p.25).

Ainda segundo o TALEB (2012, p. 25), mais da metade das crianças cegas do mundo ficaram cegas devido a causas evitáveis (15\% tratáveis e $28 \%$ previníveis), cerca de 500.000 por ano, quase uma por minuto. Enquanto outras morrem devido ao problema que causou a cegueira.

\section{VISÃO SUBNORMAL E INCLUSÃO}

A inclusão é um processo de transformação fundamental para a integração e respeito às diferenças favorecendo qualquer pessoa a exercer seus direitos. A inclusão é um meio de incentivar e desenvolver seus potenciais, garantindo experiências significativas e valorizando as individualidades.

A inclusão é um movimento educacional, mas também social e político que vem defender o direito de todos os indivíduos participarem, de uma forma consciente 


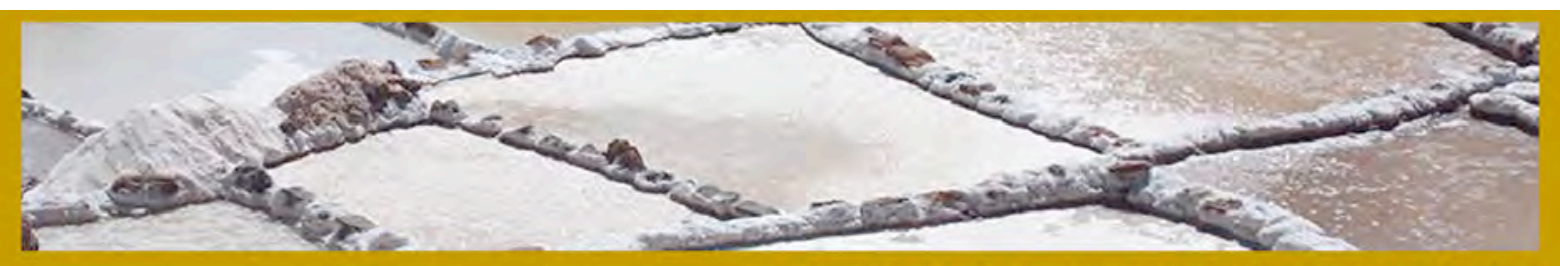

e responsável, na sociedade de que fazem parte, e de serem aceitos e respeitados naquilo que os diferencia dos outros (FREIRE ${ }^{6}, 2008$, p. 05).

As pessoas com deficiências são comumente colocadas em situação de invisibilidade.

Muito da dificuldade em desfazer a crença comum de que a luta pela inclusão seja meramente uma tentativa de reconciliação social se deve ao fato de que também muitas vezes se faz uma relação apressada com outro conceito que também ganha eco em proporções e direções geométricas: a reparação $\left(\right.$ CARVALHO $\left.^{7}, 2009, \mathrm{~s} / \mathrm{p}\right)$.

Bulgarelli $^{8}$ (2011) afirma que a inclusão verdadeira não pode ocorrer se para ser incluído for necessário mudar sua essência, pois a inclusão não deve desprezar nenhum aspecto; deve-se considerá-lo e gerar verdadeiras interações. A inclusão é aceitar a existência e os direitos dos outros e ocorre quando um maior número de pessoas for considerado participante da vida social. Para a inclusão de pessoas com deficiências visuais é importante:

Um conhecimento mais profundo de como se processa a representação mental que os cegos têm ou fazem do mundo visual, pode-nos possibilitar oferecer a essas pessoas melhores condições de reabilitação, adaptação e inclusão no mundo das pessoas portadoras de visão normal, uma vez que podemos propiciar aos portadores de limitação visual, subsídios para que saibam como melhor usar o tato, como este funciona, a fim de conhecerem até que ponto podem chegar, superando sua limitação sensória (LIMA e SILVA, 2000, s/p).

Esses são direitos elencados pela Declaração de Salamanca, em 1994, sobre princípios, políticas e práticas na área das necessidades educativas especiais,tais como:escolas regulares que possuam orientação que construam uma sociedade inclusiva e educação para todos; adotar o princípio de educação inclusiva em forma de lei ou de política; garantia em programas de treinamento de professores; todas as crianças devem aprender juntas; receber

7 Maiores informações: http://www.bengalalegal.com/inclusao. Acesso em: 29 nov. 2016

${ }^{8}$ Disponível em: http://www.bengalalegal.com/inclusao-e-diversidade. Acesso em: 29 nov. 2016 
suporte extra para assegurar uma educação efetiva e preparação apropriada de todos os educadores.

Há de se pensar na união multidisciplinar e na inclusão, trabalhando conjuntamente a família e os profissionais da área da saúde e da área educacional. Os profissionais devem ser capacitados e ter informações específicas sobre as necessidades das pessoas com visão subnormal para que sejam capazes de dar a assistência ideal.

O apoio psicológico e aconselhamento/orientação de profissionais especializados, aliados ao atendimento e intervenção dos profissionais da saúde, vão facilitar e, na maioria dos casos, garantir um desenvolvimento da criança próximo de seus pares, com reflexos positivos (MAZZARO, 2008, p. 46).

Muitas vezes a própria família torna a pessoa com visão subnormal dependente; interferindo em suas atividades de vida diárias, como amarrar cadarços, pentear os cabelos, escovar os dentes, etc. Os primeiros passos para a inclusão começam em casa; por isto o apoio e a influência da família são importantes. Dificuldades e formação deficitária dos professores relativa à educação das pessoas com deficiências visuais podem inibir a aprendizagem dos estudantes.

\subsection{AS SENSAÇÕES NA VISÃO SUBNORMAL}

As pessoas com visão subnormal utilizam a reabilitação visual desenvolvendo estratégias e habilidades para alcançarem independência e qualidade de vida. Este é um meio auxiliar para o sujeito alcançar seus objetivos. "Treinando" seus resíduos visuais e aprendendo a utilizar recursos não óticos, indicados e adaptados, podem estimular sensações capazes facilitar seu desempenho.

O sentido da visão e as sensações podem ser construídas por meio de seus significados emocionais.

$\mathrm{Na}$ ausência da visão o espaço será construído através de referências auditivas, olfativas, gustativas, proprioceptivas e táteis. O sistema de 


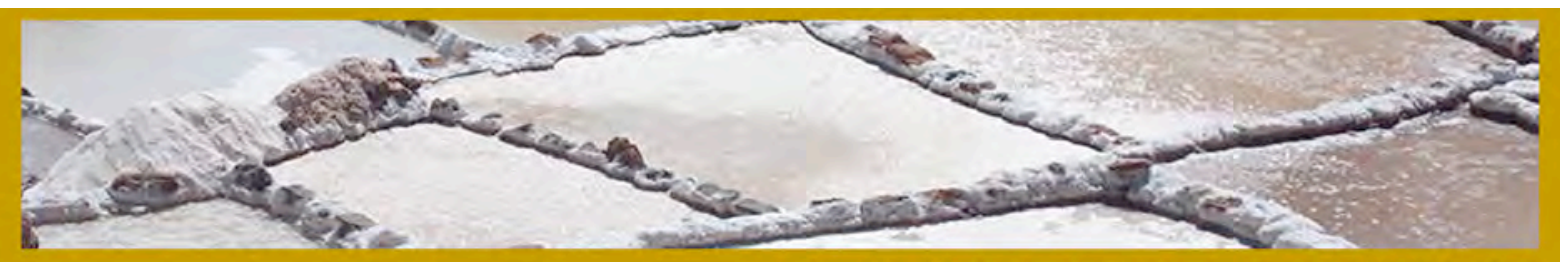

referência é completamente diferente e a estruturação do espaço é constituída de forma singular e específica. A partir de informações recolhidas dos diversos sentidos pode-se chegar a uma representação mental deste espaço, que junto com seu sentido de orientação (capacidade de situarse em relação aos objetos a sua volta), concentração e memória permitem o deslocar-se com mais facilidade em um meio externo, interiorizado (LIMA e SILVA, 2000, s/p).

Segundo o site Comunica Especial ${ }^{9}$, alguns itens que devem ser levados em consideração no processo de adaptação da pessoa com visão subnormal são: o relatório oftalmológico; o histórico médico, os condicionamentos físico-ambientais e o contexto familiar. São variáveis que devem ser readaptadas de acordo com a necessidade do estudante, além de serem necessários materiais específicos e adaptáveis para que eles trabalhem, tais como instrumentos para leitura e cálculo em Braille, livros didáticos em versão Braille, seja falado ou ampliado, etc.

Na adaptação também é necessário ter ajuda ótica e ajudas não óticas; ou seja, ajudas visuais. No processo de adaptação é preciso estimular a visualidade promovendo atividades onde o estudante fique mais independente bem como promover o desenvolvimento social.

O sistema sensório visual nos dá a conhecer o mundo através de uma grande variedade de estímulos experimentados quase que ao mesmo tempo, propiciando que distingamos uma variedade ainda maior de situações que nos poderiam ser aversivas ou mesmo fatais (LIMA e SILVA, 2000, s/p).

Para o processo de estímulo visual é importante que seja oferecido aos estudantes situações que despertem ações e emoções positivas sobre eles, pois embora as sensações sejam limitadas, são objetivas. Segundo FARINA. et. al., os "estímulos visuais têm características próprias, como tamanho, proximidade, iluminação e cor" (2006, p. 29).

A visão subnormal é uma limitação perceptiva, visto que as pessoas com DV utilizam outros meios não visuais para obterem percepções, estimulando seus outros sentidos e

\footnotetext{
${ }^{9}$ Fonte: https://comunicacaoaa.wordpress.com/baixa-visao-e-cegueira/. Acesso em: 26 nov. 2016
} 
formando suas próprias significações de mundo, seus próprios conceitos de visualidades, assim, as percepções se formam por meio de experiências significativas que carregamos ao longo da vida.

É importante ressaltar que é necessário para a inclusão, não apenas uma adaptação dos papeis sociais envolvidos no processo educacional, mas garantir para as pessoas com visão subnormal uma vida funcional, buscando garantir o respeito a diversidade e o estímulo necessário para a autonomia dos estudantes com visão subnormal.

\section{TEORIA DA COR}

A cor se faz presente simbolicamente na vida de todo ser humano, cada pessoa tem uma maneira diferente de senti-la, pois ela é uma linguagem visual, assim como a distância especial também é relativa.O significado das cores depende do contexto em que está inserido.

Para FARINA, PEREZ e BASTOS "nas artes visuais, a cor não é apenas um elemento decorativo ou estético. É o fundamento da expressão sígnica. Está ligada à expressão de valores sensuais, culturais e espirituais" (2006, p. 05).

\footnotetext{
Algumas cores são construídas além da sensibilização fisiológica dos cones (...). Assim acontece com a percepção da cor metálica, da cor transparente, da cor translúcida, etc., que são percebidas em interação com a percepção de texturas, através dos contrastes (SILVEIRA, 2005, p. 176).
}

A percepção dos contrastes é reforçada a partir da constância cromática, a tendência que os objetos têm de manter a sua cor, mesmo sob o efeito de luzes coloridas que interfiram em sua percepção. Mas, para Dondis (2007, p. 61) a verdadeira luz vem da tonalidade. Segundo Silveira (2005) a constância cromática acontece devido à complementação cromática: 
guardados na memória, a partir do vasto conjunto imagético adquirido no ato interpretativo de "ver". Os objetos estão alocados na memória juntamente com todos os seus parâmetros perceptíveis. Quando a falta de um deles é detectada (no caso, a cor), acontece a sua complementação (SILVEIRA, 2005, p. 173).

No caso de pessoas com visão subnormal é possível a percepção cromática a partir da visão residual, que é diferenciada para cada pessoa. A memória cromática pode ou não estar presente, de acordo com o tipo de deficiência e sua causa. As cores podem ser associadas a formas, texturas e sensações. A percepção das formas e das cores nas pessoas com visão subnormal estudadas no ICPAC, segundo seus relatos orais, tem relação com suas vivências pessoais.

A cor não pode ser percebida isoladamente, de forma desvinculada dos outros parâmetros perceptivos dos objetos alocados na memória (cheiro, tamanho, textura, som, gosto, etc.). Ela é um elemento apreendido durante toda a vida de um indivíduo e não há o caminho de volta (SILVEIRA, 2005, p. 178).

A percepção visual e a memória cromática estão intrinsecamente relacionadas ao funcionamento neuronal e ao mecanismo da visão. As atividades com artes visuais podem estimular tanto a diferenciação cromática quanto a percepção da forma. Goethe afirmou que:

As sensações de cores que surgem em nossa mente são também moldadas pela nossa percepção - pelos mecanismos da visão e pela maneira como nosso cérebro processa tais informações (apud ARAÚJO ${ }^{10}, 2013, \mathrm{~s} / \mathrm{p}$ ).

\footnotetext{
${ }^{10}$ Disponível em: http://www.antroposofy.com.br/wordpress/a-teoria-das-cores-de-goethe/. Acesso 29 nov. 2016.
} 
Figura 2 - Círculo das cores criado por Goethe em 1810

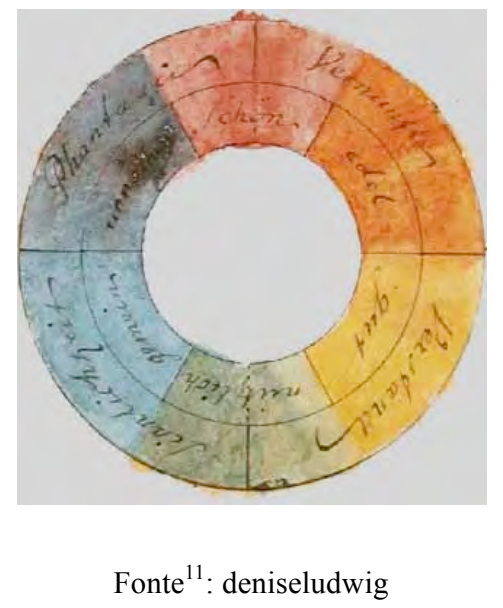

Dondis afirma que "a informação visual também pode ter uma forma definível, seja através de significados incorporados, em forma de símbolos, ou de experiências compartilhadas no ambiente e na vida" (2007, p. 32). Considerando que:

a cor é uma condição e, como tal, uma característica do estilo de vida de uma época - integra uma determinada maneira de ver as coisas. É inegável que toda cor tem um espaço que lhe é próprio, mas é também inegável que esse espaço faz parte da cor, de acordo com as concepções culturais que o fundamentam (FARINA et al., 2006, p. 17).

Há inúmeros fatores que podem influenciar as pessoas na escolha das cores, entre elas o meio em que a pessoa vive, o temperamento, a idade, o momento vivido, etc., além de um peso psicológico e cultural (op. cit., 2006, p. 25)

Assim como o significado de cada cor, seu efeito também depende de onde ela está aplicada, qual o contexto em que será utilizada, pois

\footnotetext{
11 Disponível em: <http://deniseludwig.blogspot.com.br/2013/02/arte-e-teoria-das-cores.html>.
} Acesso: 30 nov. 2016. 
Os dados visuais podem transmitir informações: mensagens específicas ou sentimentos expressivos, tanto intencionalmente, com um objetivo definido, quanto obliquamente, como um subproduto da utilidade (DONDIS, 2007, p. 183).

Para a Teoria Perceptiva de Gibson (1974 apud SILVEIRA, 2005, p. 178) "a percepção [é] como um composto apreendido, impossibilitando a percepção das características isoladas dos objetos. Segundo ele, apreendemos na memória, através da percepção visual" (apud SILVEIRA, 2005, p. 178).

Nas imagens as cores são cheias de significados e estão presentes diariamente em nossas vidas; podendo identifica-las facilmente na natureza e nas artes visuais, publicidade, moda, design, etc. Mas, essas cores só fazem sentido se aplicadas adequadamente, devido ao seu impacto e apelo visual e as reações que podem causar na população. As cores estão presentes no cotidiano urbano e podem ser fundamentais para identificação da locomoção e mobilidade, seja em áreas públicas ou privadas, sua identificação adequada pode favorecer a mobilidade e a acessibilidade das pessoas com visão subnormal.

\subsection{ANÁLISE DA EXPERIÊNCIA}

Inicialmente aplicamos com os estudantes dois questionários orais, um questionário social e outro sobre as cores. Assim foi possível conhecê-los melhor e verificar a limitação de cada um. Todos os estudantes que participaram da pesquisa têm visão subnormal ${ }^{12}$.

Tabela 2: Perfil dos participantes da pesquisa

\begin{tabular}{|l|l|l|}
\hline \multicolumn{1}{|c|}{ NOME } & \multicolumn{1}{|c|}{ IDADE } & \multicolumn{1}{c|}{ RELAÇÃO COM A COR } \\
\hline I & 8 anos & $\begin{array}{l}\text { Enxerga cores a curta distância, conseguindo identificar } \\
\text { cores primárias e confundindo cores secundárias }\end{array}$ \\
\hline $\mathrm{P}$ & 6 anos & $\begin{array}{l}\text { Identifica muito bem as cores, sabendo também a } \\
\text { mistura de cores. }\end{array}$ \\
\hline
\end{tabular}

\footnotetext{
${ }^{12} \mathrm{O}$ aluno $\mathrm{Y}$. tem apenas percepções luminosas e identifica as cores por aromas, tato, etc.
} 


\begin{tabular}{|l|l|l|}
\hline $\mathrm{Y}$ & 16 anos & $\begin{array}{l}\text { Muita dificuldade em enxergar as cores, nunca havia } \\
\text { identificado as cores, apesar do contato cotidiano. }\end{array}$ \\
\hline
\end{tabular}

Fonte: acervo dos pesquisadores, 2016.

Figura 3: Cores mais pintadas por cada estudante

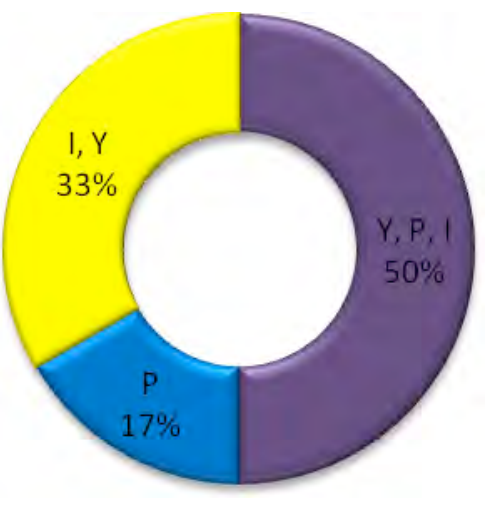

Fonte: acervo dos pesquisadores

Figura4: Cores de preferência dos estudantes

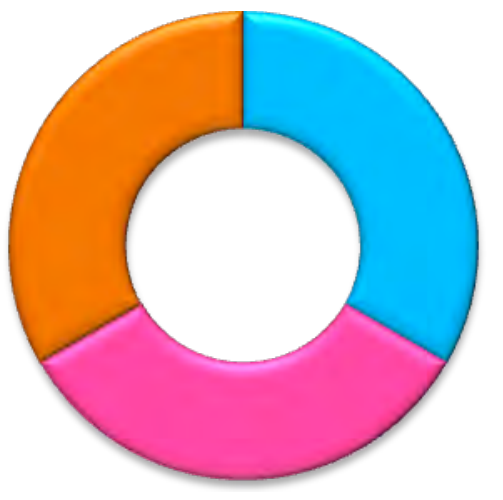

回 Azul

Rosa

Castanho

Fonte: acervo dos pesquisadores 


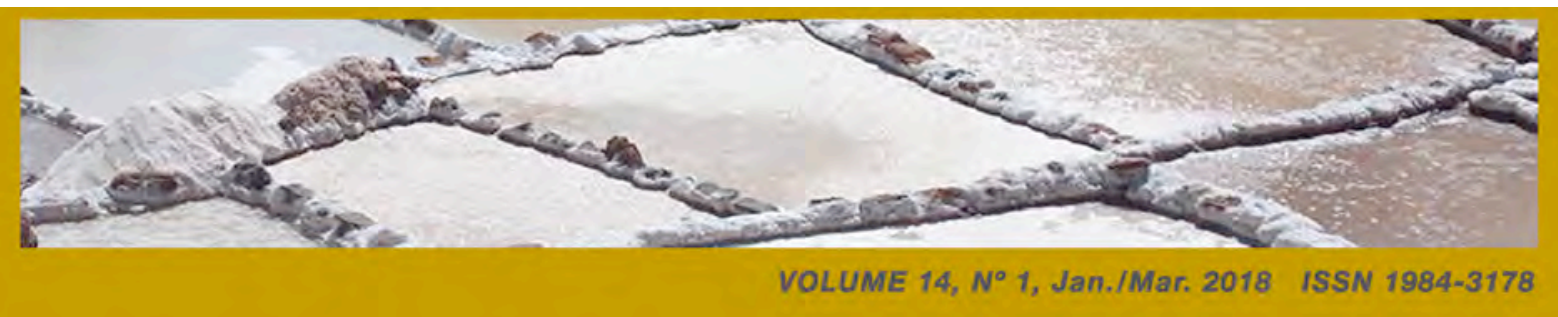

Maiores dificuldades figura fundo:

Figura 51: Folha amarela com objeto verde

\section{Cor original}

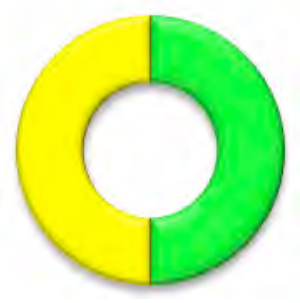

Cor vista

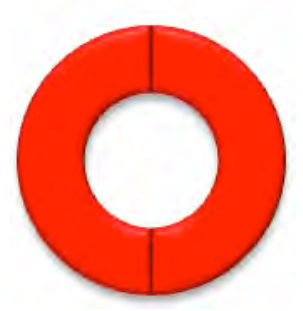

Fonte: acervo dos pesquisadores

Figura 6: Folha verde com objetos verde e azul

\section{Cor original}

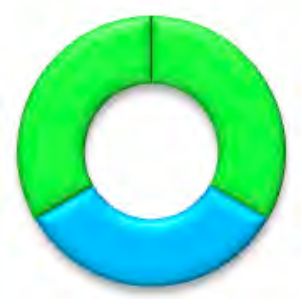

\section{Cor vista}

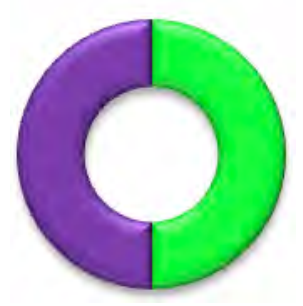

Fonte: acervo dos pesquisadores 
A uma distância de $30 \mathrm{~cm}$ um estudante não conseguiu identificar as cores exatas que estavam expostas para ele, enxergando vermelho onde seria amarelo e verde. Mas a uma distância média de $5 \mathrm{~cm}$ identificou as cores corretamente. Isto pode ser explicado por FARINA. et. al. quando afirmam que:

Ao ter necessidade de focalizar um objeto mais próximo, é preciso ter uma acomodação do olho; onde há uma contração dos músculos que forçam os ligamentos e diminuem a tensão. O que, consequentemente, permite uma focalização perfeita do objeto na retina (2006, p. 47).

Já a uma distância de $15 \mathrm{~cm}$ o estudante não identificou o azul; enxergando roxo e identificou perfeitamente o verde. A esta mesma distância e com o auxílio de uma lanterna, o estudante identificou as cores corretamente porque, segundo FARINA et al, "podemos conseguir a sensação do branco pela combinação de apenas três cores, que são o verde, azul violeta e vermelho alaranjado, pois estas cores estimulam determinados cones" (op. cit. 2006, p. 4). Também podemos associar esta questão ao fato de que:

A cor depende, pois, da natureza das coisas que olhamos, da luz que as ilumina, e ela existe enquanto sensação registrada pelo cérebro. $\mathrm{O}$ olho recebe a cor como mensagem e a transmite ao cérebro, receptor do indivíduo. Portanto, a cor existe quando produzida por estímulos luminosos na retina e por reações do sistema nervoso (op. cit., 2006, p. 61).

A distância máxima que os estudantes conseguiram identificar as cores/formas foram 30 centímetros, apresentando grandes dificuldades em identificar cor sobre a mesma outra cor, identificando apenas manchas de outras cores que não eram as expostas, enquanto que figura com as cores branca e preta foi identificada apenas a de maior luminosidade, o branco. E nas cores sob luz intensa, identificam a cor como mais clara. Nos tecidos eles não conseguiam identificar as formas, apenas a cor que predominava. 

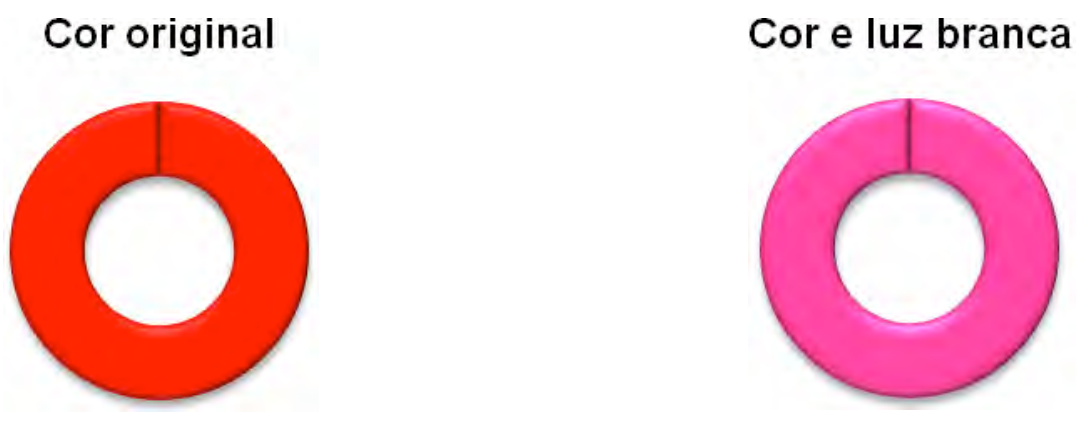

Fonte: acervo dos pesquisadores

Trabalhamos com práticas diferentes com cada estudante, visto que suas limitações e necessidades são diferentes. São situações diferentes, portanto, apresentaram resultados diferentes. Trabalhamos a mistura de cores primárias, identificação de cores e formação das cores secundárias, utilizando tecidos estampados, folhas coloridas, tintas guache, frutas e verduras para identificação de formas e utilizamos a luz da lanterna para a identificação de objetos coloridos e colagens de tampinhas e massas de biscuit.

Para que o estudante que tinha menor resíduo de visão se familiarizasse com as cores utilizamos texturas de tecidos, frutas e verduras, tintas guache, massa de biscuit e a luz da lanterna. Com as tintas guaches observamos que ele verificava a temperatura do pote de tinta, identificando assim as cores. Com as frutas e as verduras ele sentia seu aroma, sem que tocasse nestes alimentos. Com os tecidos ele identificava pelo tato, fazendo associações a outros tecidos e aos aromas. E para que ele pintasse utilizamos tintas extraídas de frutas, verduras e folhas, também fizemos associações a outras frutas, a plantas, objetos, etc., que tinham as mesmas cores.

A projeção das cores não funcionou bem, pois embora conseguissem identificar as cores, a luz era muito forte e fazia com os olhos lacrimejassem muito, o que fez com que essa experiência fosse descartada durante a pesquisa. 


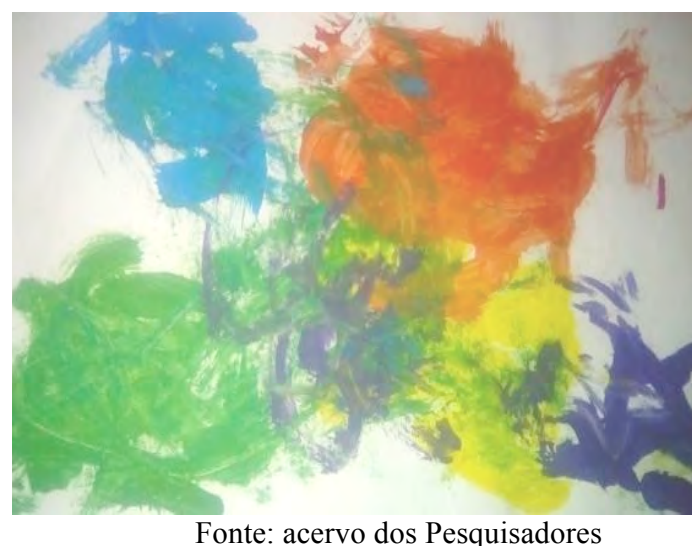

Quando o questionário oral foi aplicado novamente, os estudantes já conseguiam identificar algumas misturas de cores. E também alguns já conseguiam identificar em tonalidades claras.

Os participantes da pesquisa não costumam escolher a cor de suas roupas, embora consigam identificar alguns tecidos e estampas, identificando com mais facilidade tecidos claros e sem estampas. Quando perguntados a respeito de sinais de trânsito, alguns informaram que conseguem identificar vendo o sinal de muito perto, mas quando estão em um veículo não conseguem enxergar as cores devido à interferência da luz e excesso de velocidade, embora saibam dizer quais cores estão no sinal de trânsito. Apenas um estudante não soube dizer as cores dos sinais de trânsito e informou que sabe que o sinal está fechado apenas quando é um sinal que têm efeito sonoro, mas ele relatou que não anda nas ruas sozinho.

$\mathrm{Na}$ identificação dos banheiros, não souberam informar qual placa era o banheiro masculino e o feminino, relataram que sabia qual eram os respectivos banheiros devido a suas localizações dentro da instituição. 
Figura 9: Pintura com tintas naturais

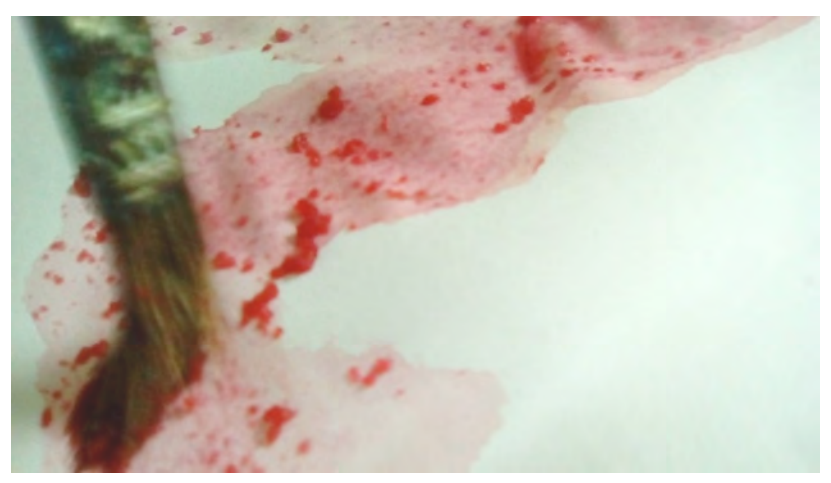

Fonte: acervo dos Pesquisadores

Também realizamos com os estudantes uma experiência sensorial com algumas maquetes táteis de obras cedidas pela Pinacoteca UFPB que foram criadas sem uma disciplina de educação inclusiva ministrada pelo professor Robson Xavier. Os estudantes gostaram, principalmente, das obras que tem mais detalhes. As cores foram mais fáceis de serem identificadas, e ao tocar as obras conseguiram identificar as cores de fundos, as linhas, as formas, etc. Relataram não ter tido contato antes com nenhuma obra de arte e que as obras sensoriais eram "boas" de se tocarem. Em obras maiores, foi mais fácil a identificação da cor, mas as formas ficaram difíceis de perceber. 


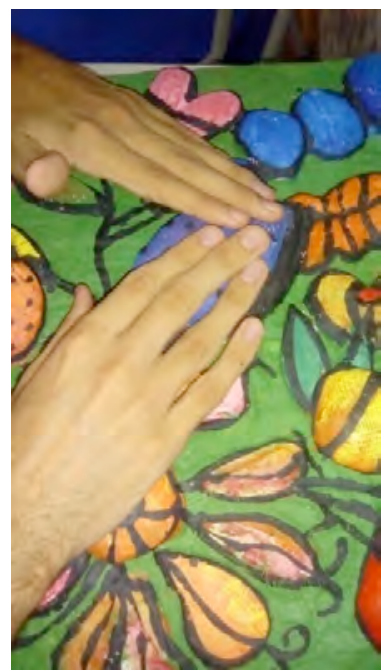

Fonte: Acervo dos Pesquisadores

\section{CONSIDERAÇÕES FINAIS}

No início da pesquisa os estudantes identificavam as cores por associação; enquanto uns estudantes estavam começando a conhecer as cores, outros queriam fazer "experiências" misturando todas as cores aleatoriamente. Durante as aulas foram feitas algumas perguntas repetidas, em que eles responderam de maneira diferente cada uma das vezes.

A percepção de mundo das pessoas com visão subnormal é obtida por meio da exploração de seus sentidos residuais. As informações que estes sentidos dão nem sempre são completas; o que os leva a um processo de significação de cores mais lento do que os normovisuais, pois as pessoas com visão subnormal não são estimuladas para a percepção das cores, o que faz com que, a princípio, tenham uma relação distante, percebendo apenas com maior facilidade as cores puras ou as de sua preferência, a partir da intuição e necessidade. 
O excesso ou a falta de luz é a maior dificuldade em fazê-los ver as cores, sejam cores luz em ambientes excessivamente claros ou escuros. A luz forte deixa seus olhos sensíveis, se exposta por muito tempo próxima aos seus olhos causam irritabilidade, vermelhidão, etc. Enquanto um ambiente muito escuro faz com que eles não detectem as cores, identificando apenas "manchas" escuras. Mesmo após a presença de luz mantem a dificuldade em enxergar tonalidades próximas.

Partindo das observações em contato dos participantes com as maquetes táteis de obras de arte, percebemos que as imagens fazem sentido para eles após o toque, pois, por este meio eles têm noção de dimensão das obras, de figura fundo, cores, formas, linhas, etc. Podendo assim, sensorialmente, tornar a obra significativa.

Nos trabalhos expressivos realizados com o grupo pesquisado, fizeram pinturas feitas com tintas guache e sucos extraídos das frutas e verduras. Além das pinturas, trabalharam com colagem com as massas de biscuit, tampinhas de garrafa e tecidos estampados.

Identificamos que quanto maior o estímulo para a identificação das cores os estudantes com visão subnormal melhorarm a percepção visual e a significação das imagens das artes visuais. O trabalho com pintura deixou de ser apenas rabiscos descompromissados e passou a transmitir vivências, linguagens significativas e suas representatividades de mundo, favorecendo a continuidade do seu contato com as imagens da arte e com a identificação das cores no cotidiano.

\section{REFERÊNCIAS}

ARAÚJO, Leonardo Carneiro. A teoria das cores de Goethe. Disponível em: $<$ http://www.antroposofy.com.br/wordpress/a-teoria-das-cores-de-goethe/>. 2013. Acesso em: $29 \mathrm{de}$ novembro de 2016.

BAIERLE, Mariana. O que é baixa visão? Porto Alegre. Disponível em:

$<$ http://tresgotinhas.com.br/voce-sabe-o-que-e-baixa-visao/>. Acesso em: 2 de novembro de 2016.

BULGARELLI, Reinaldo. Inclusão e Diversidade. 2011. Disponível em: $<$ http://www.bengalalegal.com/inclusao-e-diversidade>. Acesso em: 29 de novembro de 2016.

CARVALHO, Lucio. Inclusão, Sociedade e Outros Abusos Conceituais. 2009. Disponível em: $<$ http://www.bengalalegal.com/inclusao> Acesso em: 29 de novembro de 2016. 


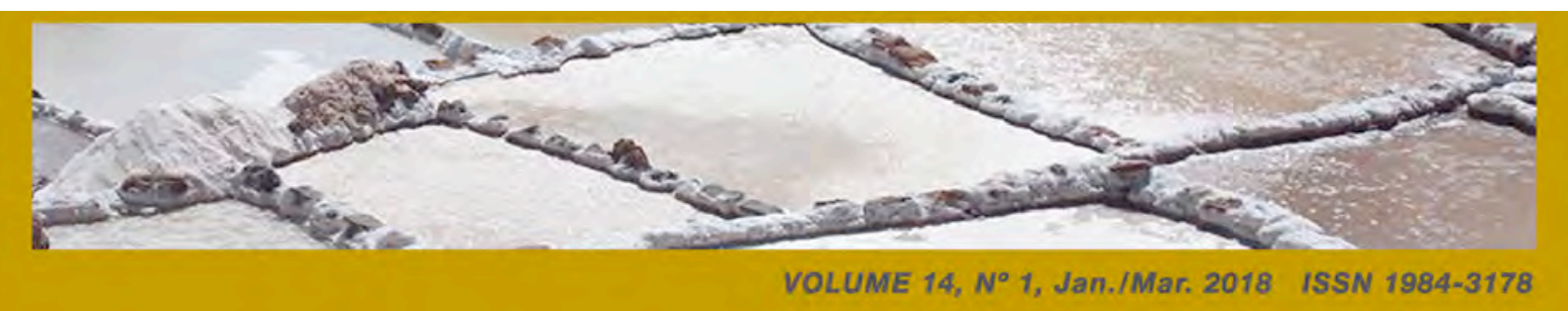

COMUNICA ESPECIAL. Baixa Visão e Cegueira. Disponível em: $<$ https://comunicacaoaa.wordpress.com/baixa-visao-e-cegueira/>. Acesso em: 26 de novembro de 2016.

CONDE, Antonio J. M. Deficiência visual: a cegueira e a baixa visão. Disponível em: http://www.bengalalegal.com/cegueira-e-baixa-visao. Acesso em: 20 de maio de 2016.

DONDIS, Donis A. Sintaxe da Linguagem Visual. Trad. Jefherson Luis Camargo. $3^{\text {a }}$. Ed. São Paulo: Martins Fontes, 2007.

FARINA, Modesto. PEREZ, Clotilde. BASTOS, Dorinho. Psicodinâmica das cores em comunicação. $5^{\text {a }}$. Ed. São Paulo: 2006.

FREIRE, Sofia. Um olhar sobre a inclusão. Revista da Educação, Vol. XVI, nº 1, p. 5, 2008. Disponível

em: $<$ http://repositorio.ul.pt/bitstream/10451/5299/1/Um\%20olhar\%20sobre\%20a\%20Inclus\%C3\%A3o.pd f >. Acesso em: 30 de Novembro de 2016.

FUNDAÇÃO DORINA. Deficiência Visual. São Paulo. s/d. Disponível em: $<$ http://www.fundacaodorina.org.br/deficiencia-visual/>. Acesso em: 31 de outubro de 2016.

ICPAC. Conheça. Disponível em: <http://icpac.com.br/conheca>. Acesso em 30 de Novembro de 2016.

LIMA, Francisco José de. SILVA, José Aparecido. Algumas considerações a respeito do sistema tátil de crianças cegas ou de visão subnormal. In: Revista Benjamin Constant. Rio de Janeiro: IBC, Número 17, Ano 6, 2000.

MAZZARO, José Luiz. Políticas Públicas Para inclusão educacional: o Professor e o aluno com baixa visão. In: Revista Ambiente \& Educação. Porto Alegre: FURG, V.1 - n. 2, ago./dez. 2008.

RICHARDSON, Roberto Jarry. et. al. Pesquisa Social: métodos e técnicas. $3^{\text {a }}$. Ed. São Paulo: Atlas, 2012.

SILVEIRA, Luciana Martha. A percepção cromática na imagem fotográfica em preto e branco: uma análise em nove "eventos de cor". In: Actas do III Sopcom, VI Lusocom e III Congresso Ibérico das Ciências da Comunicação - Informação, Identidades e Cidadania. Covilhã - Portugal: Universidade da Beira Interior, 2005. Disponível em: http://www.bocc.ubi.pt/pag/silveira-lucianamartha-percepcao-cromatica-imagem-fotografica-preto-branco.pdf. Acesso em: 20 de dezembro de 2017.

TALEB, Alexandre; FARIA, Marco Antonio Rey de; ÁVILA, Marcos; MELLO, Paulo Augusto de Arruda. As Condições de Saúde Ocular no Brasil. 1ª. Ed. São Paulo: 2012

VENTORINI, Silvia Helena. A experiência como fator determinante na representação espacial da pessoa com deficiência visual. São Paulo: UNESP, 2009.

YIN, R. K. Estudo de caso: planejamento e métodos. 3a. Ed. Porto Alegre: Bookman, 2005. 


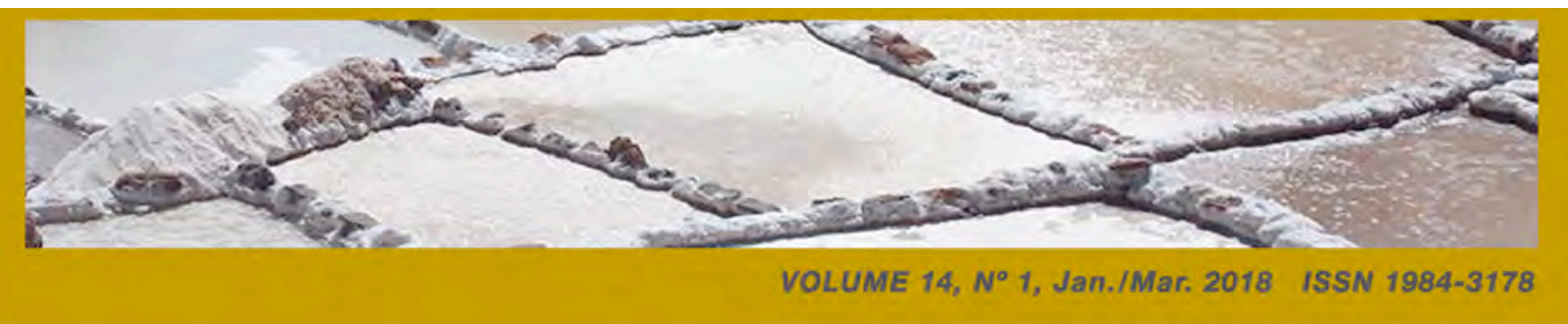

Recebido em 25 de junho de 2017 Aprovado em 15 de novembro de 2017 